archives-ouvertes

\title{
Cross machine investigation of magnetic tokamak dust; Morphological and elemental analysis
}

M de Angeli, P Tolias, C Conti, D Ripamonti, F Ghezzi, C Arnas, J Irby, M Jerab, B Labombard, G Maddaluno

\section{To cite this version:}

M de Angeli, P Tolias, C Conti, D Ripamonti, F Ghezzi, et al.. Cross machine investigation of magnetic tokamak dust; Morphological and elemental analysis. Fusion Engineering and Design, Elsevier, 2021. hal-03194282v2

\section{HAL Id: hal-03194282 \\ https://hal.archives-ouvertes.fr/hal-03194282v2}

Submitted on 3 May 2021

HAL is a multi-disciplinary open access archive for the deposit and dissemination of scientific research documents, whether they are published or not. The documents may come from teaching and research institutions in France or abroad, or from public or private research centers.
L'archive ouverte pluridisciplinaire HAL, est destinée au dépôt et à la diffusion de documents scientifiques de niveau recherche, publiés ou non, émanant des établissements d'enseignement et de recherche français ou étrangers, des laboratoires publics ou privés. 


\title{
Cross machine investigation of magnetic tokamak dust: Morphological and elemental analysis
}

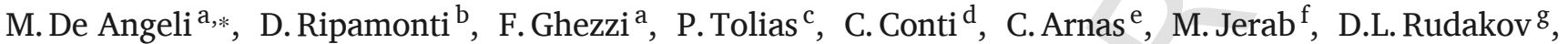 \\ C.P. Chrobak ${ }^{h}$, J. Irby ${ }^{i}$, B. LaBombard ${ }^{i}$, B. Lipschultz ${ }^{j}$, G. Maddalunok
}

a Institute for Plasma Science and Technology, CNR, via Cozzi 53, 20125 Milano, Italy

${ }^{\mathrm{b}}$ Institute of Condensed Matter Chemistry and Energy Technologies, CNR, via Cozzi 53, Milano, Italy

c Space and Plasma Physics - KTH Royal Institute of Technology, Teknikringen 31, 10044 Stockholm, Sweden

${ }^{\mathrm{d}}$ Istituto di Scienze del Patrimonio Culturale, CNR, via Cozzi 53, 20125 Milano, Italy

e CNRS, Aix-Marseille Université, Laboratoire PIIM, campus St Jérôme, 13397 Marseille, France

${ }^{\mathrm{f}}$ Institute of Plasma Physics of the CAS, Za Slovankou 3, 18200 Prague 8, Czech Republic

${ }^{g}$ University of California San Diego, La Jolla, CA 92093, USA

${ }^{\mathrm{h}}$ General Atomics, PO Box 85608, San Diego, CA 92186-5608, USA

${ }^{\mathrm{i}}$ M.I.T. Plasma Science and Fusion Center, 175/190 Albany Street, Cambridge, MA 02139, USA

${ }^{j}$ Department of Physics, University of York, Heslington, York YO10 5DD, UK

${ }^{\mathrm{k}}$ ENEA, C.R. Frascati, Via E. Fermi 45, 00044 Frascati (Roma), Italy

\section{A R T I C L E I N F O}

\section{Keywords}

Magnetic dust

Dust

FTU dust

Compass dust

Alcator dust

DIII-D dust

\begin{abstract}
A B S T R A C T
The presence of magnetic dust can be an important issue for future fusion reactors where plasma breakdown is critical. Magnetic dust has been collected from contemporary fusion devices (FTU, Alcator C-Mod, COMPASS and DIII-D) that feature different plasma facing components. The results of morphological and elemental analysis are presented. Magnetic dust is based on steel or nickel alloys and its magnetism is generated by intense plasma-material interactions. In spite of the strong similarities in terms of morphology and composition, X-ray diffraction analysis revealed differences in the structural evolution that leads to non-trivial magnetic responses.
\end{abstract}

\section{Introduction}

The presence of dust in fusion devices constitutes an important issue with safety and operational implications [1-4]. Despite the fact that ferromagnetic dust has been detected in a number of machines [5-8], magnetic dust has never been systematically investigated probably owing to the obvious absence of bulk magnetic materials in the vessel components. In particular, comprehensive dust collection activities in most tokamaks have never attempted a characterization of the magnetic properties of the sampled dust population [9-15].

It has been suggested that ferromagnetic dust can be generated in tokamaks by a non-equilibrium austenite-to-ferrite phase transformation that is induced by rapid temperature quenching in the presence of strong external magnetic fields [8]. Moreover, there is strong experimental evidence of pre-plasma remobilization of ferromagnetic dust in FTU that has been further supported by theoretical estimates [16]. This provided motivation for a re-evaluation of the old hypothesis concerning the possible impact of prematurely re-mobilized dust on the toka- mak start-up $[5,16]$. Accurate predictions of the extent of such impact require reliable input concerning the overall amount and the size distribution of the magnetic dust.

The present work reports the first cross-machine dust collection study that focuses on the magnetic properties of tokamak dust and constitutes the first attempt to map the magnetic dust inventory of contemporary fusion devices. A morphological and elemental analysis of magnetic dust sampled from FTU, Alcator C-Mod, COMPASS and DIII-D is presented. These characteristics are compared to draw general conclusions concerning magnetic dust in tokamaks.

\section{Magnetic dust collection and vessel composition}

In the present work, the term magnetic dust refers to any particulate that can be isolated from a specimen under the effect of a strong permanent magnet, i.e. discussion is not confined to ferromagnetic dust but extends to strongly paramagnetic dust. The dust collection activities were carried out with different methods and in different locations for the tokamaks investigated. Magnetic dust from FTU, Alcator C-Mod and

* Corresponding author.

E-mail address: marco.deangeli@istp.cnr.it (M. De Angeli) 
COMPASS was separated, by means of a strong magnet, from an entire dust batch collected by vacuuming. Magnetic dust from DIII-D was collected in-situ by means of a permanent magnet dragged around the vessel during a scheduled machine shut-down. The above difference naturally introduces limitations in the comparison between DIII-D and the other tokamaks.

The tokamaks under investigation are characterized by different plasma-facing material composition and different working toroidal magnetic field strengths. As summarized in Table 1, FTU and COMPASS feature plasma-facing materials that can directly seed magnetic dust (namely stainless steel and Inconel respectively), while Alcator C-Mod and DIII-D can only indirectly seed magnetic dust through diagnostic components or structural materials. Moreover, FTU and Alcator are compact machines with high toroidal magnetic field up to $8 \mathrm{~T}$, whereas COMPASS and DIII-D have moderate field up to $2.2 \mathrm{~T}$, implying a variable ability of magnetic dust production. Even though interest on plasma-facing materials is currently focused on the slightly paramagnetic tungsten and the slightly diamagnetic beryllium, as we shall discuss, the machine combination studied herein can be considered as representative of existing and future devices with respect to magnetic dust generation.

The dust batches that were selected for analysis are listed in the following. (a) FTU. The dust was collected by gross vacuuming around the vessel floor and was meshed out into two different size groups [8]. The batch with sizes $<210 \mu \mathrm{m}$ was considered in the present investigation. (b) Alcator C-Mod. The dust was collected by vacuuming the floor, the upper areas of the lower outer divertor, the horizontal areas and beneath the "FG" sector of the outer divertor in 2007. (c) COMPASS. Three dust batches were collected by vacuuming in different locations: the batch $\mathrm{Co} 2$ was collected inside the east port duct, the batch Co3 was collected inside the south port duct and the batch $\mathrm{Co} 4$ was collected in the divertor at the Langmuir probe feed-through position. (d) DIII-D. Magnetic dust was collected by a permanent magnet dragged around bottom surfaces of an outboard midplane and bottom ports during an entry vent. In this case, the overall amount was minuscule.

Table 2 catalogues the dust batch names, weights and the analysis performed. It should be noted that dust from all the tokamak devices could be covered by boron as a result of boronisation activities. In addition, only for FTU, dust could be covered by lithium compounds courtesy of the liquid lithium limiter $[8,17]$. Both elements are highly reactive with oxygen $(\mathrm{O})$ and are difficult to detect by EDX analysis either due to the low sensitivity at low energies or due to partial overlapping with other elements.

\section{Table 1}

Vessel material composition at the time of the dust collection together with the maximum strength of the toroidal magnetic field. TZM is a molybdenum dominated alloy (Ti $0.5 \mathrm{wt} \%$, Zr $0.1 \mathrm{wt} \%$, Mo balance); SS stands for stainless steel; Inconel is a Ni based super-alloy. Note also that, during the 2007 Alcator C-Mod experimental campaign, a toroidal row of $\mathrm{W}$ tiles was inserted in the strike point region [13].

\begin{tabular}{llllll}
\hline $\begin{array}{l}\text { Tokamak } \\
\text { device }\end{array}$ & $\begin{array}{l}\text { Year of } \\
\text { dust } \\
\text { collection }\end{array}$ & $\begin{array}{l}\text { Wall } \\
\text { material }\end{array}$ & $\begin{array}{l}\text { Machine } \\
\text { configuration }\end{array}$ & $\begin{array}{l}\text { Limiter } \\
\text { or } \\
\text { divertor } \\
\text { material }\end{array}$ & $\begin{array}{l}\text { Maximum } \\
\text { toroidal } \\
\text { magnetic } \\
\text { field }\end{array}$ \\
\hline FTU & 2013 & SS & Limiter & TZM & $8.0 \mathrm{~T}$ \\
$\begin{array}{l}\text { Alcator C- } \\
\text { Mod } \\
\text { COMPASS }\end{array}$ & 2007 & Mo & Divertor & Mo & $8.0 \mathrm{~T}$ \\
DIII-D & $2014 / 15$ & $\begin{array}{l}\text { Inconel } \\
625\end{array}$ & Divertor & Graphite & $2.1 \mathrm{~T}$ \\
\hline
\end{tabular}

Table 2

Dust batches investigated. "N/A" suggests that the amount of dust is too scarce to be weighted, "XRD" stands for X-ray diffraction, "SEM" for scanning electron microscopy and "EDX" for energy-dispersive X-ray analysis. The fractions are in weight percentage.

\begin{tabular}{lllll}
\hline $\begin{array}{l}\text { Dust batch } \\
\text { name }\end{array}$ & $\begin{array}{l}\text { Magnetic amount/ } \\
\text { fraction }\end{array}$ & $\begin{array}{l}\text { Non-magnetic amount/ } \\
\text { fraction }\end{array}$ & $\begin{array}{l}\text { SEM- } \\
\text { EDX }\end{array}$ \\
\hline Ft1 & $12.57 \mathrm{~g} / 25.0 \%$ & $50.28 \mathrm{~g} / 75.0 \%$ & Yes & Yes \\
$\mathrm{Al} 1$ & $0.074 \mathrm{~g} / 27.4 \%$ & $0.196 \mathrm{~g} / 72.6 \%$ & Yes & Yes \\
$\mathrm{Co} 4$ & $0.042 \mathrm{~g} / 17.6 \%$ & $0.196 \mathrm{~g} / 82.4 \%$ & Yes & Yes \\
$\mathrm{Co} 3$ & N/A & N/A & No & Yes \\
$\mathrm{Co} 2$ & N/A & N/A & No & Yes \\
D1 & N/A & N/A & No & Yes \\
\hline
\end{tabular}

\section{Analysis of magnetic dust}

The magnetic dust collected from the four aforementioned tokamaks is based either on stainless steel (SS) or on Nickel (Ni) alloys that originate from different plasma facing components (PFCs) such as walls, divertor or limiter tiles, diagnostics or antennas. In terms of shape, the dust can be roughly categorized as flakes, splashes and spheroids.

Dust flakes. The majority of dust grains in all magnetic batches are flakes based on SS. Characteristic examples of flake-shaped dust that was collected from the four tokamaks are illustrated in Fig. 1. Their maximum dimension ranges from few tens up to $\sim 1500 \mu \mathrm{m}$ depending on the fusion device of origin. EDX analysis revealed that the flakes have low oxygen content ( $<6$ at $\%$ on average) with the exception of FTU flakes which feature a much higher $\mathrm{O}$ concentration, probably due to the presence of $\mathrm{Li}$. The average $\mathrm{Fe} / \mathrm{Cr}$ ratio is $3.0 \div 5.0$, estimated on the grains analyzed from each device batch, to be compared with that of the standard SS AISI304/316 grade (3.3-4.0). It should be noted that many debris in Alcator and COMPASS definitely originate from machining, performed either in-vessel or transported from outside. In fact, some debris have "accordion-like" structures typical of mechanical shavings, see Fig. 2(a,b). This has been verified by a morphological comparison with SS shaves obtained from workshop milling and lathing activities.

Splashed droplets. Splash-shaped magnetic dust has been found in all devices except DIII-D. This is expected owing to the absence of vacuuming in the present DIII-D collection as well as the enhanced adhesion of splashes [18] or of immobile dust with high temperature pre-history [19]. Splashes are based on SS or Ni alloys, see Fig. 3. Their maximum dimension ranges from 100 up to $\sim 500 \mu \mathrm{m}$ and they have a low $\mathrm{O}$ concentration (10 at $\%$ on average). The SS-based splashes possess a $\mathrm{Fe} / \mathrm{Cr}$ ratio of 3.5-3.9.

Spheroids. Sphere-like magnetic grains have been collected in all tokamaks under investigation as either SS- or Ni-based grains with diameters ranging from $\sim 40$ up to $\sim 250 \mu \mathrm{m}$. Sphere-like dust can be divided into two classes; those with clear dendrite-like surface texture (see Fig. 4) and those without dendrite-like surface texture (see Fig. 5). The O content of the un-textured SS spheroids is lower than that of the textured SS spheroids ( 25 at $\%$ vs. 45 at $\%$ on average), probably due to their higher surface porosity. The average $\mathrm{Fe} / \mathrm{Cr}$ ratio is $2.5-4$ in both classes. The un-textured grains from DIII-D have a highly irregular surface but feature high oxygen content. The presence of a clear surface texture depends on the dynamic cooling rate after melting [20], which is not possible to estimate solely based on post-mortem evidence. The presence of both textured and un-textured grains in the magnetic dust batches lead to the conclusion that the grain cooling rate is not a critical parameter for the austenite-to-ferrite phase transformation. Note that Ni-based sphere-like dust has been detected in the FTU, COMPASS Co2 and DIII-D batches. 


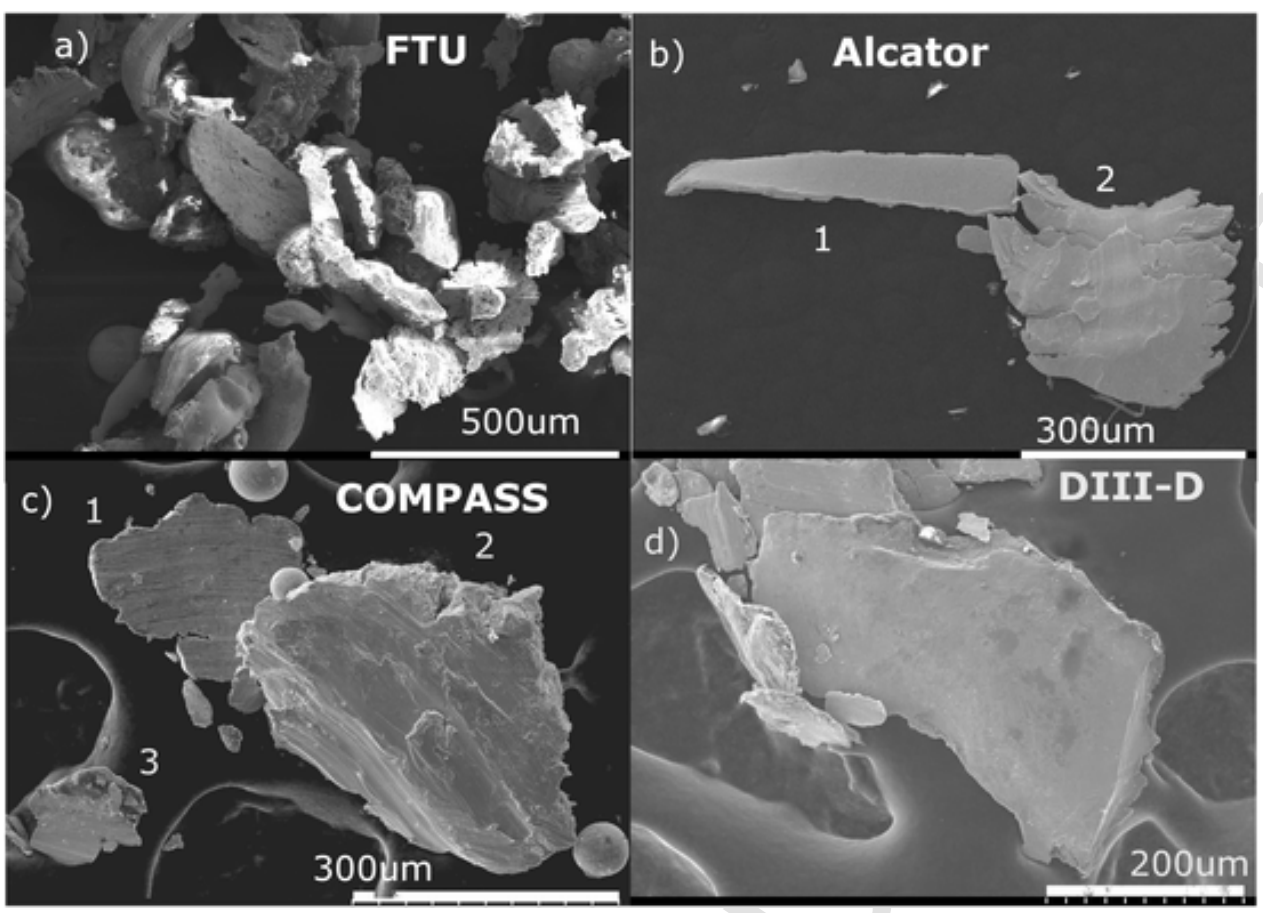

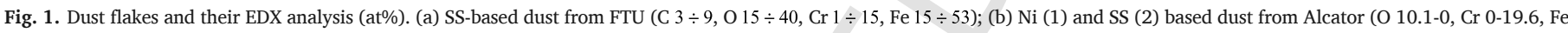

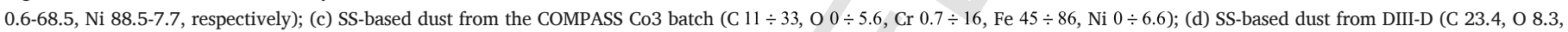
Cr 11.3, Fe 46.6, Ni 6.3).
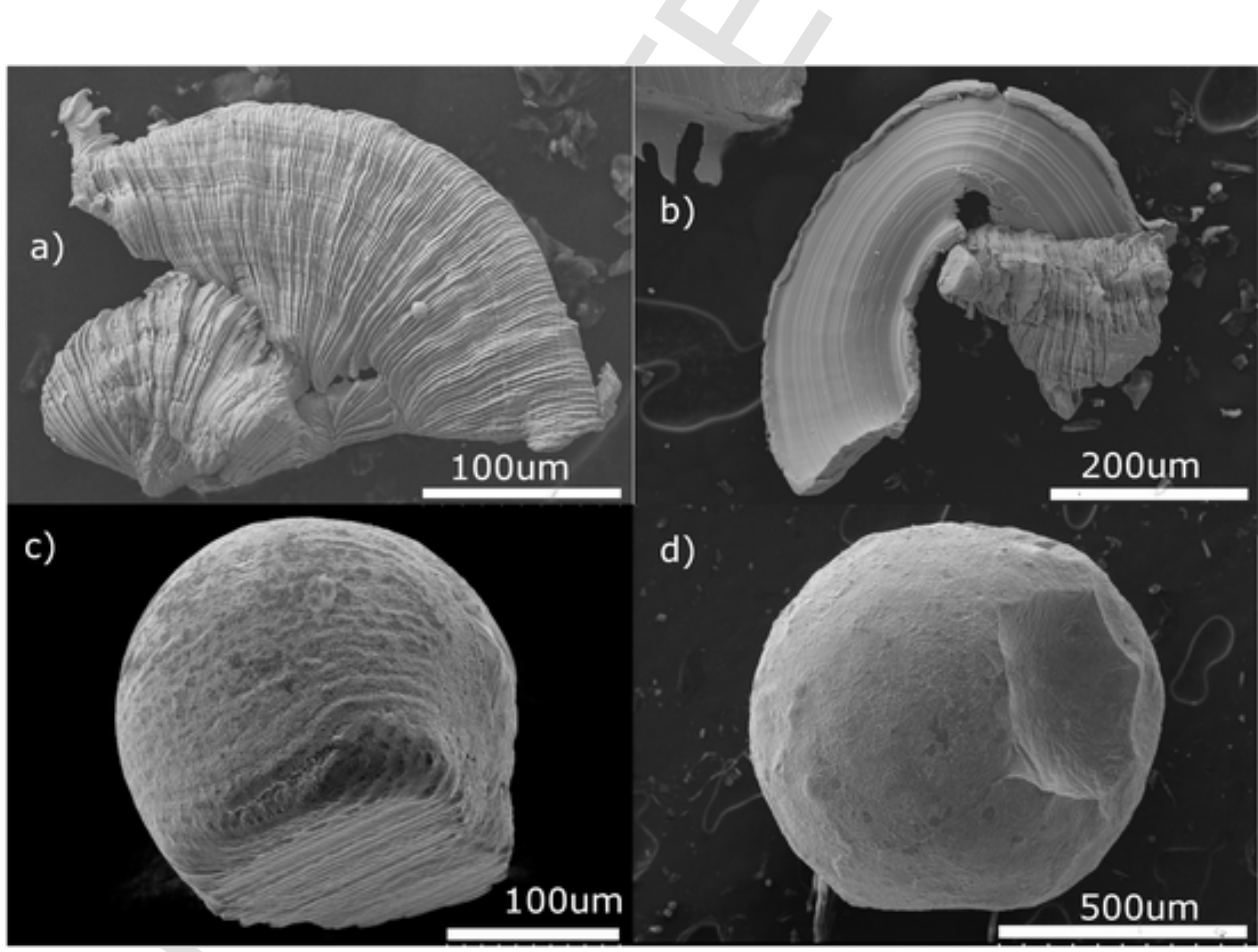

d)

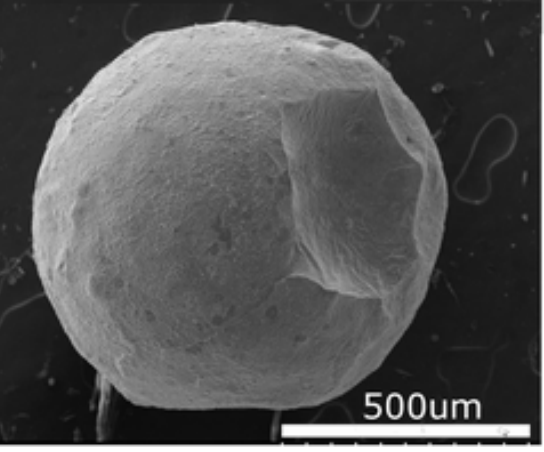

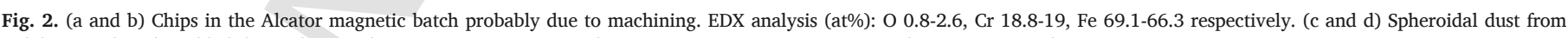
in-lab Inconel studs welded on SS plates and EDX (at\%); (c) magnetic dust (O 63.7, Cr 18.6, Fe 1.4, Ni 0); (d) non-magnetic dust (O 58.7, Cr 28.3, Fe 1.2, Ni 0.5).

Aiming to establish whether spheroidal magnetic dust can originate from in-vessel welding activities (a common practice inside the DIII-D vessel), dust has been collected after in-lab welding of Inconel 625 studs on Inconel 625 or SS AISI316 plates used in DIII-D. The analysis of the produced spheroidal grains revealed that only welding involving SS materials could generate magnetic grains, while pure Ni-based grains are not magnetic. Furthermore, the welding-produced magnetic
SS dust seems to have been exposed to much higher heat loads and presents some irregular surface texture structure (though not well defined) compared to dust collected in tokamaks. Examples of magnetic and non-magnetic SS grains produced by in-lab welding activity are illustrated in Fig. 2c and d. Note the high $\mathrm{O}$ content and low $\mathrm{Fe} / \mathrm{Cr}$ ratio $(\ll 1)$.

X-ray Diffraction Analysis. XRD analysis was carried out on some magnetic dust batches (see Table 2). All batches analyzed were con- 


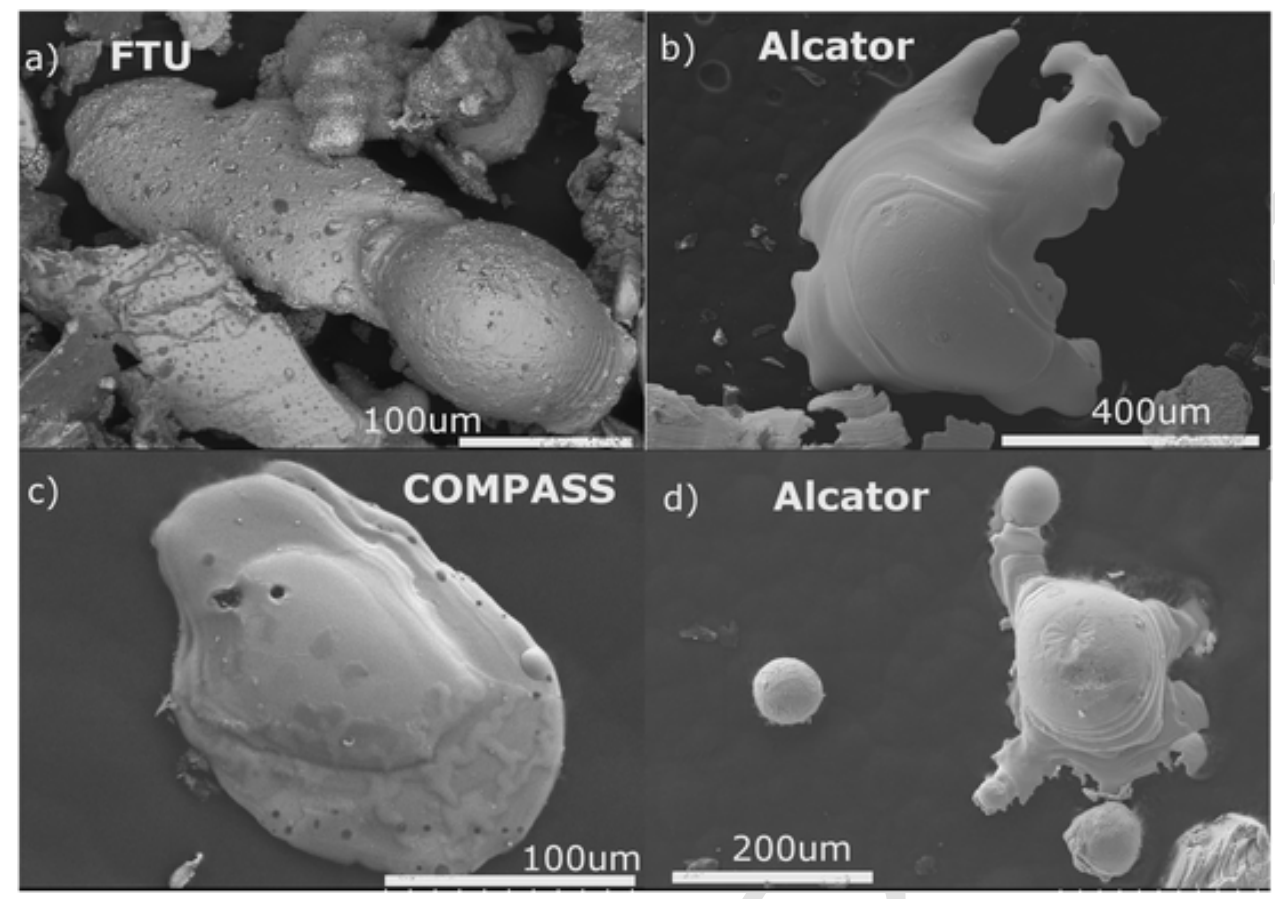

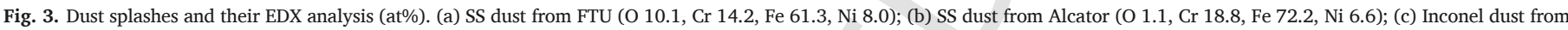
the COMPASS Co2 batch (B 24.6, O 4.8, Cr 14.3, Fe 0.9, Ni 37.7), no splashes in the Co3,4 batches; d) SS dust from Alcator (O 15.9, Cr 16.3, Fe 51.7, Ni 7.2).

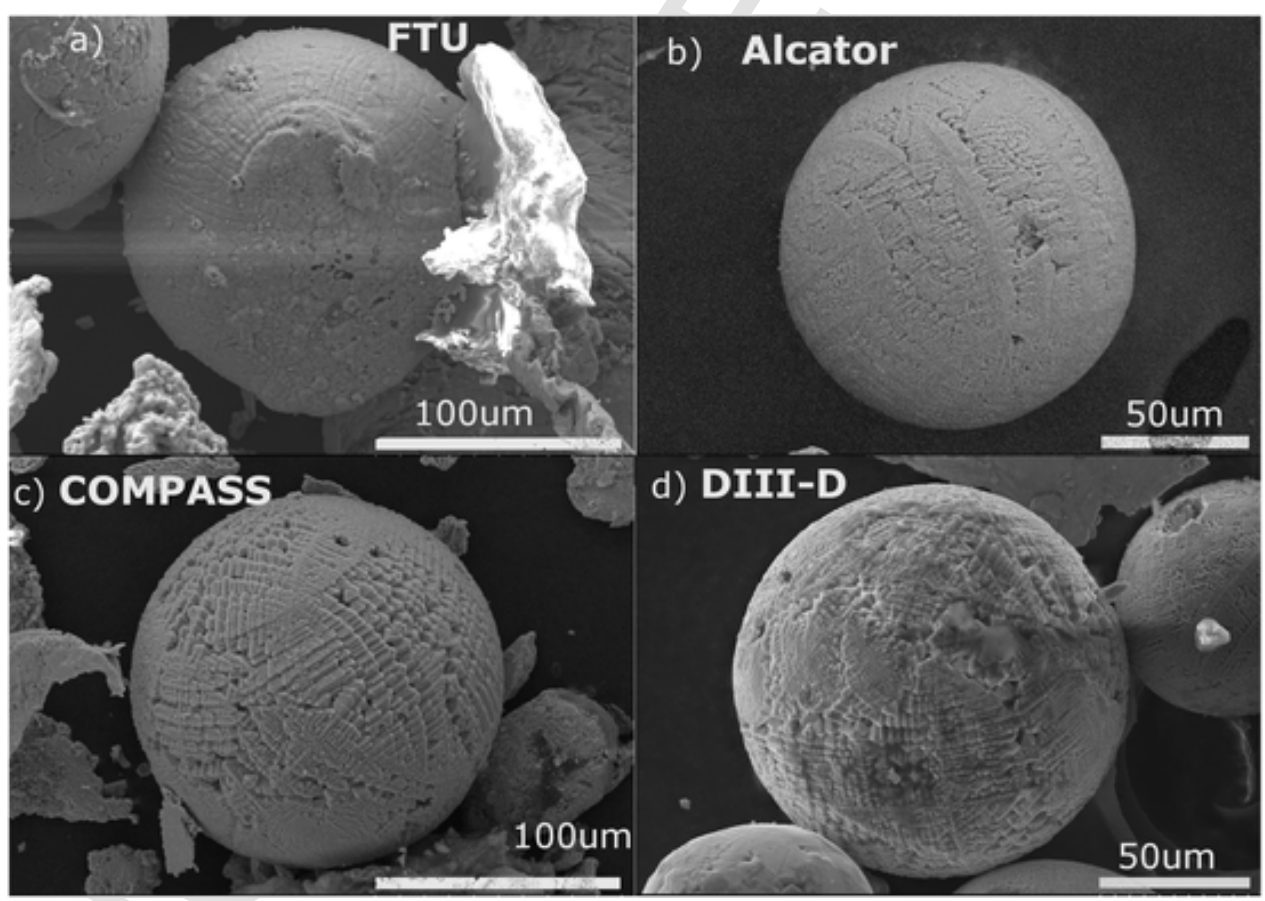

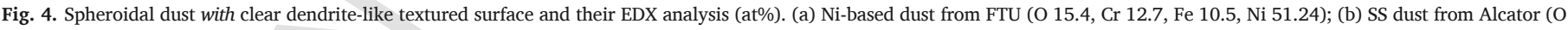
53.7, Cr 8.0, Fe 32.8, Ni 4.8); (c) SS dust from the COMPASS Co4 batch (O 48.3, Cr 8.7, Fe 32.1, Ni 3.3); (d) SS dust from DIII-D (C 26.9, O 41.6, Cr 7.2, Fe 21.7, Ni 1.9).

firmed to be composed of SS and Ni alloys. Some of them, namely the ones from FTU and COMPASS, feature an increased ferrite peak compared to the peak of the standard untreated AISI304/316 SS material, see Fig. 6. This can be explained by the austenite-to-ferrite phase transformation that occurs in re-solidified spherical droplets and splashes when embedded in a strong magnetic field environment [8]. In addition, the FTU spectrum reveals the probable presence of martensite, typical of rapid cooling down of molten grains, a peculiarity that can be attributed to the fact that FTU is a cryogenic device $[21,22]$.
On the other hand, the XRD spectrum of Alcator magnetic dust (Fig. 6, red line) is similar to the standard spectrum of untreated AISI316 steel (dashed line in Fig. 6), where the austenitic Fe- $\gamma$ peak is much higher than the ferrite Fe- $\alpha$ one; Fe- $\alpha$ about $10 \%$ of Fe $\gamma$. This can be explained by the fact that most Alcator magnetic grains were flakes, which as discussed above are believed to primarily originate from either in-vessel or ex-vessel machining. A more detailed analysis of the XRD results will be reported in a separate work. 

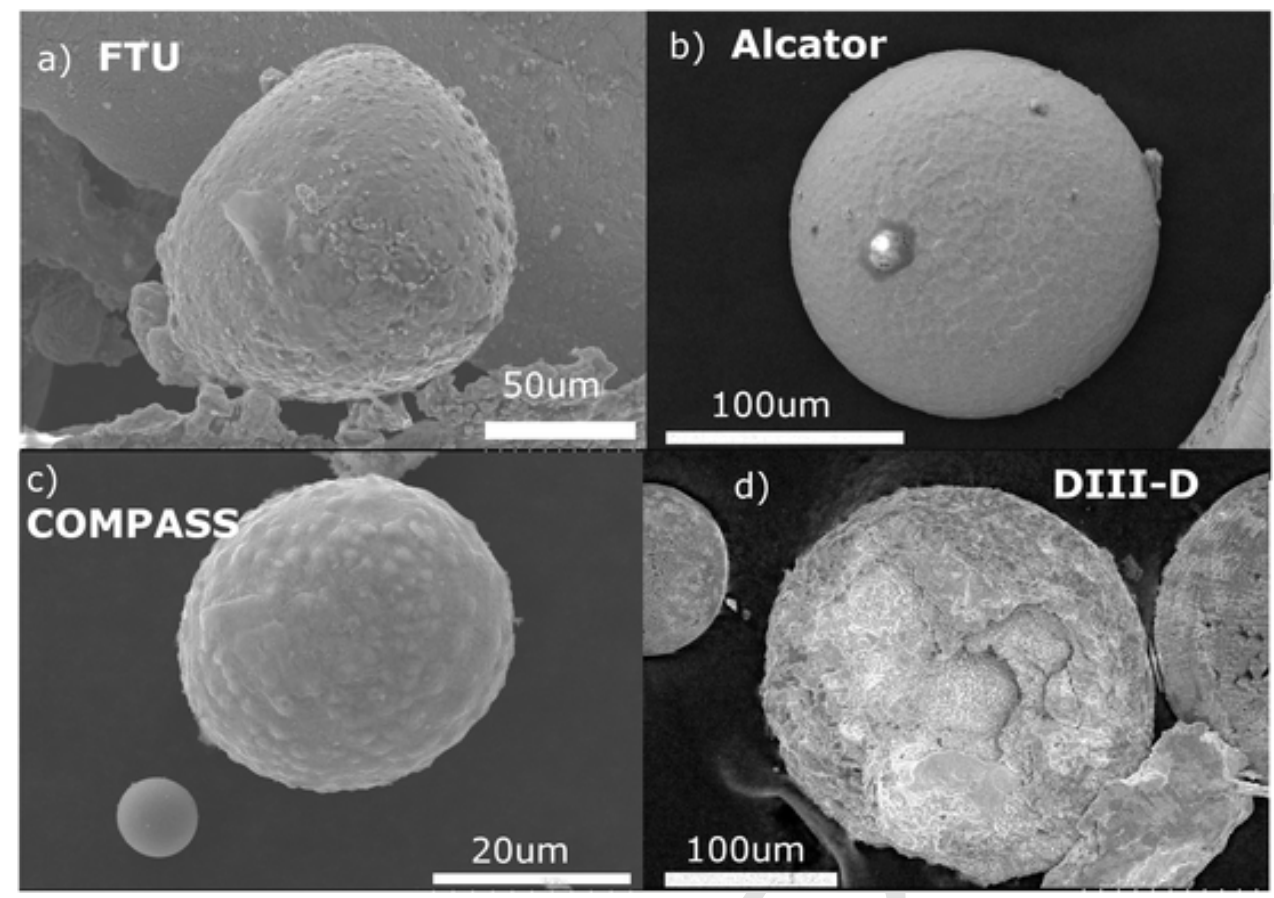

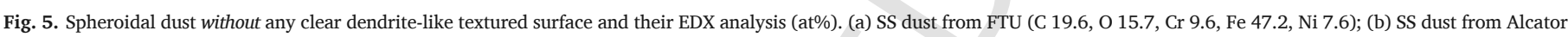
(C 0, O 0, Cr 21.2, Fe 70.0 Ni 8.0); (c) SS dust from the COMPASS Co4 batch (C 50.4, O 9.1, Cr 7.9, Fe 27.4, Ni 4.4); (d) SS dust from DIII-D (C 53.4, O 23, Cr 4.7, Fe 15.8, Ni 2.3).

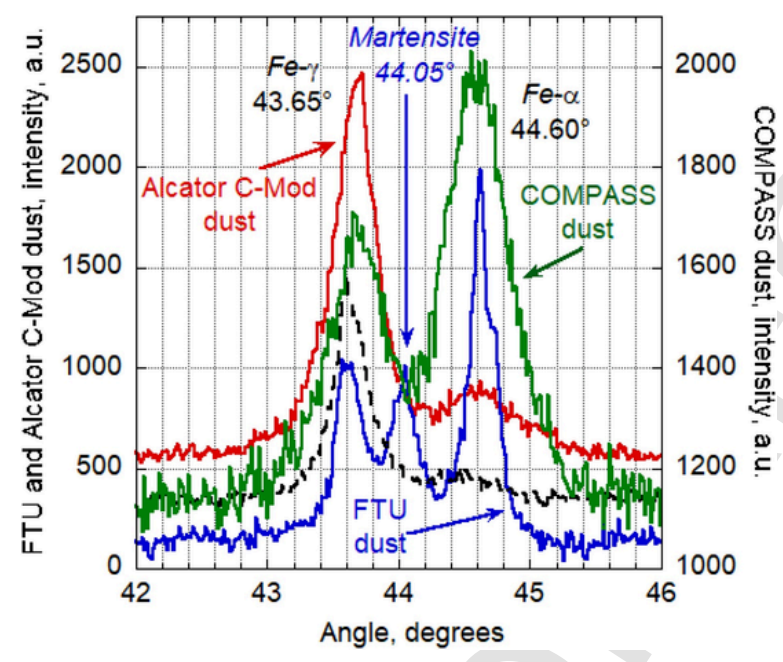

Fig. 6. XRD spectra of the Alcator C-Mod (red), FTU (blue) and COMPASS Co4 (green) magnetic dust batches. The spectrum of untreated AISI316 steel is also shown with the black dashed line. (For interpretation of the references to color in this figure legend, the reader is referred to the web version of this article.)

\section{Discussion and conclusions}

This investigation catalogues the magnetic dust inventory of fusion devices that are equipped with different plasma-facing materials. Concerning its surface morphology, magnetic dust is encountered in the shape of flakes, splashes or spheroids with dimensions that range from few microns up to several hundreds of microns.

As far as the chemical composition is concerned, magnetic dust is based on steel or nickel alloys. The low surface content of oxygen on dust splashes and some spheroidal grains suggests that they originated from plasma-material interactions and not from in-vessel welding activities that can be a common practice. The latter possibility can be excluded for the majority of grains because of the morphological and chemical differences between plasma-generated and welding-generated dust, namely the high oxygen concentration and the $\mathrm{Fe} / \mathrm{Cr}<1$ ratio in dust that is produced by in-lab welding. This is the so-called $\mathrm{Cr}$ surface segregation phenomenon that typically accompanies very high temperature treatment [23], as in welding, and leads to a higher O content owing to the formation of $\mathrm{Cr}$ oxides. The collection of Ni-based spheroidal dust (in DIII-D) further supports the claim that such grains do not originate from welding activities, as discussed in Section 3.

X-ray Diffraction analysis has demonstrated the different nature of dust magnetism depending on the fusion device. In particular, in magnetic dust collected from FTU and COMPASS, the presence of ferrite and/or martensite structures is revealed that constitutes evidence of SS dust magnetic phase transition under intense plasma heat loads [8]. The presence of an ambient magnetic field plays a role in magnetic phase retention during dust resolidification, as observed by some authors $[24,25]$, but the magnetic field strength does not appear to be a key point, since magnetic phase transitions were detected in devices with high and moderate toroidal magnetic field. Probably, this stems from the fact that magnetic fields of the order of few Tesla suffice to saturate the magnetic domains of ferritic grains. On the other hand, the large quantity of SS flakes collected in Alcator C-Mod is revealed to be in the native austenite state.

In the case of ferromagnetic spherical dust, it has already been demonstrated that the magnetic moment force owing to the toroidal field can overcome both the gravitational and the adhesion force leading to pre-plasma remobilization [16]. In the case of strongly paramagnetic dust, a simple evaluation of the magnetic force that is exerted on a spherical grain in presence of toroidal field gradients suggests that it is several times larger than gravity. This indicates that, in principle, any SS grain could be classified as magnetic dust. The complications due to the non-spherical morphology of the flakes and a comparison with adhesion forces $[26,27]$ will be addressed in future work.

Overall, a non-negligible amount of magnetic dust has been collected from the tokamaks considered in this work. This holds for FTU and COMPASS that can directly seed magnetic dust from the first wall, but also holds for Alcator C-Mod and DIII-D that can only indirectly seed magnetic dust from their diagnostics and antennas. Taking into ac- 
count that the ITER diagnostic first wall is composed of stainless steel [28], it is possible that great amounts of magnetic dust will be produced in ITER, where plasma breakdown is critical. This is confirmed by the latest projections for dust generation in ITER, which anticipate comparable amounts of stainless steel and tungsten dust by the end of the fusion power operation phase [29]. In particular, the lower estimate is $8 \mathrm{~kg} \mathrm{~W}$ and $9 \mathrm{~kg}$ SS dust, whereas the upper estimate is $37 \mathrm{~kg} \mathrm{~W}$ dust and $23 \mathrm{~kg}$ SS dust [29]. In the prospective of the possible extended utilization of reduced-activation ferritic-martensitic steels in DEMO [30], it is possible that large amounts of magnetic dust will also be generated beyond ITER. The understanding of the nature and origin of magnetic dust is an essential step towards the reliable modelling of its pre-plasma remobilization and of its interference with the start-up of future fusion devices.

\section{Disclaimer}

This report was prepared as an account of work sponsored in part by an agency of the United States Government. Neither the United States Government nor any agency thereof, nor any of their employees, makes any warranty, express or implied, or assumes any legal liability or responsibility for the accuracy, completeness, or usefulness of any information, apparatus, product, or process disclosed, or represents that its use would not infringe privately owned rights. Reference herein to any specific commercial product, process, or service by trade name, trademark, manufacturer, or otherwise does not necessarily constitute or imply its endorsement, recommendation, or favoring by the United States Government or any agency thereof. The views and opinions of authors expressed herein do not necessarily state or reflect those of the United States Government or any agency thereof.

\section{Conflict of interest}

The authors declare no conflict of interest.

\section{Declaration of Competing Interest}

The authors report no declarations of interest.

\section{Acknowledgments}

This work is supported in part by the U.S. Department of Energy under DE-FC02-04ER54698. DIII-D data shown in this paper can be ob- tained in digital format by following the links at https://fusion.gat.com/ global/D3D_DMP.

\section{References}

[1] J.P. Sharpe, D.A. Petti, H.-W. Bartels, Fusion Eng. Des. 63-64 (2002) 153

[2] J. Roth, E. Tsitrone, A. Loarte, et al., J. Nucl. Mater. 390-391 (2009) 1.

[3] S.I. Krasheninnikov, R.D. Smirnov, D.L. Rudakov, Plasma Phys. Control. Fusion 53 (2011) 083001.

[4] P. Tolias, S. Ratynskaia, M. De Angeli, et al., Plasma Phys. Control. Fusion 58 (2016) 025009.

[5] J. Winter, Phys. Plasmas 7 (2000) 3862.

[6] D. Ivanova, M. Rubel, et al., Phys. Scr. T138 (2009) 014025.

[7] A.N. Novokhatsky, A.E. Gorodetsky, V.K. Gusev, et al., Proc. 38th EPS Conf. Vol. 35G P5.066, Strasbourg, France, 2011.

[8] M. De Angeli, L. Laguardia, G. Maddaluno, et al., Nucl. Fusion 55 (2015) 123005.

[9] D.L. Rudakov, A. Litnovsky, W.P. West, et al., Nucl. Fusion 49 (2009) 085022

[10] N. Endstrasser, V. Rohde, M. Balden, et al., Phys. Scr. T145 (2011) 014021.

[11] M. Balden, N. Endstrasser, P.W. Humrickhouse, et al., Nucl. Fusion 54 (2014) 073010.

[12] A. Baron-Wiechec, E. Fortuna-Zalesna, J. Grzonka, et al., Nucl. Fusion 55 (2015) 113033.

[13] C. Arnas, J. Irby, S. Celli, G. De Temmerman, et al., Nucl. Mater. Energy 11 (2017) 12.

[14] M. Rubel, A. Widdowson, J. Grzonka, et al., Fusion Eng. Des. 136 (2018) 579.

[15] S. Peillon, G. Dougniaux, M. Payet, et al., Nucl. Mater. Energy 24 (2020) 100781.

[16] M. De Angeli, E. Lazzaro, P. Tolias, et al., Nucl. Fusion 59 (2019) 106033.

[17] F. Ghezzi, L. Laguardia, M.L. Apicella, et al., Appl. Surf. Sci. 428 (2018) 124

[18] S. Ratynskaia, P. Tolias, I. Bykov, et al., Nucl. Fusion 56 (2016) 066010.

[19] P. Tolias, M. De Angeli, S. Ratynskaia, et al., Nucl. Mater. Energy 24 (2020) 100765.

[20] S. Kou, Welding Metallurgy, John Wiley \& Sons, NJ, 2003.

[21] A. Pizzuto, et al., Fusion Sci. Technol. 45 (2004) 422.

[22] E. Franconi, et al., J. Nucl. Mater. 179-181 (1991) 267.

[23] K.H. Lo, C.H. Shek, J.K.L. Lai, Mater. Sci. Eng. R 65 (2009) 39.

[24] J.H. Lee, T. Fukuda, T. Kakeshita, J. Phys. Conf. Ser. 156 (2009) 012013.

[25] J. Choi, T. Fukuda, T. Kakeshita, S605, J. Alloy Compd. 577S (2013) S605.

[26] P. Tolias, Fusion Eng. Des. 133 (2018) 110

[27] P. Tolias, Surf. Sci. 700 (2020) 121652.

[28] R.A. Pitts, B. Bazylev, J. Linke, et al., J. Nucl. Mater. 463 (2015) 748.

[29] G. De Temmerman, R.A. Pitts, Progress in analysis of PWI issues for ITER and research needs, Joint Annual Meeting of JET2 \& WP PFC, 9-10/11/2020, 2020.

[30] J. Roth, K. Sugiyama, V. Alimov, et al., J. Nucl. Mater. 454 (2014) 1. 